\title{
Hepatosplenic T Cell Lymphoma Involved Small Vessels of Central Nervous
}

\section{System}

\section{Jose Armando Justinico Castro* | Juan Carlos Arango Viana}

*Correspondence: Jose Armando Justinico Castro

Address: Department of Pathology, University of Antioquia, Colombia

e-mail $\bowtie$ : jose.justinico@udea.edu.co

Received: 24 October 2020; Accepted: 03 November 2020

Copyright: (C) 2020 Justinico Castro. This is an open-access article distributed under the terms of the Creative Commons Attribution License, which permits unrestricted use, distribution, and reproduction in any medium, provided that the original work is properly cited.

\section{ABSTRACT}

Hepatosplenic T-cell lymphoma (HSTCL) is a rare, aggressive type of peripheral T - cell lymphoma characterized by infiltration and proliferation of atypical T-cells within the sinusoids of the spleen, liver, and bone marrow. This case report consists of a young male, who was admitted to a local hospital with a history of unexplained fever, odynophagia, and rash, initially mimicking infectious disease. The patient died due to multiorgan failure and the correct diagnosis only was accomplished in the autopsy. This case highlights the difficulty of diagnosing HSTCL and the necessity of considering it in patients with unknown origin fever with hyperferritinemia.

Keywords: Hepatosplenic T-Cell Lymphoma, Hyperferritinemia, Central Nervous System

\section{Introduction}

Hepatosplenic T-cell lymphoma (HSTCL) is an aggressive and rare disease originating from gamma-delta lymphocytes. These cells play a role in innate immunity and they are native from thymus precursors. This condition is characterized by cytopenias, hepatosplenomegaly without significant lymphadenopathy, and an aggressive clinical course.

Histologically is characterized by the involvement of sinusoids of liver, spleen, and bone marrow. Immunophenotypically are CD3+, CD56 +/-, CD4 -, CD8 +/- and CD5 -/+. Most gamma delta cases express the $\mathrm{V}$ delta 1 chain. The cells express the cytotoxic granule-associated proteins TIA1, granzyme $\mathrm{M}$ and can be positive or negative to perforin. This neoplasia is not associated with Epstein Barr virus (EBV)

The infiltration in other organs and tissue different from bone marrow is rare. There is little information about of compromise of the central nervous system (CNS). We report a 25-year-old man, 
healthy with unknown origin fever and extreme hyperferritinemia who die from multiorgan failure. The autopsy showed hepatosplenomegaly and histological study displayed atypical lymphocytes in sinusoids of spleen and bone marrow, and small vessels in CNS, skin, and lung.

\section{Case Report}

A 25-years-old man, who lived in a rural area of Colombia consulted to a local hospital with a month-long history of fever $\left(3^{\circ} \mathrm{C}\right)$, odynophagia, malaise, arthralgia, myalgia, and erythematous reticular rash. He was treated with symptomatic therapy without improvement. He persisted with symptoms and additionally muscular weakness; therefore, he was taken into hospital. During hospitalization, neutrophils, creatinine, and hepatic tests were all rising, and Ferritin was found extremely high $(175.188 \mathrm{mg} / \mathrm{dl})$. The blood cultures were negatives and he took a course of antibiotics for ten days (Cefepime + vancomycin) and transferred to a high-level hospital due to lack of response. The patient had a progressive general deterioration with persistent fever (peaks). Computed tomography scans of the brain, chest, abdomen, and pelvis, and an abdominal Ultra-sonography gave all normal results. He developed multi-organ failure and required vasopressor support, mechanical ventilation, and hemodialysis. He was empirically treated with Piperacillin/Tazobactam and doxycycline for a possible bacterial infection including Rickettsiosis and leptospirosis. Additionally, he received human immunoglobulin for suspected Still's disease. Finally, the condition worsened, and he died 14 days after admission.

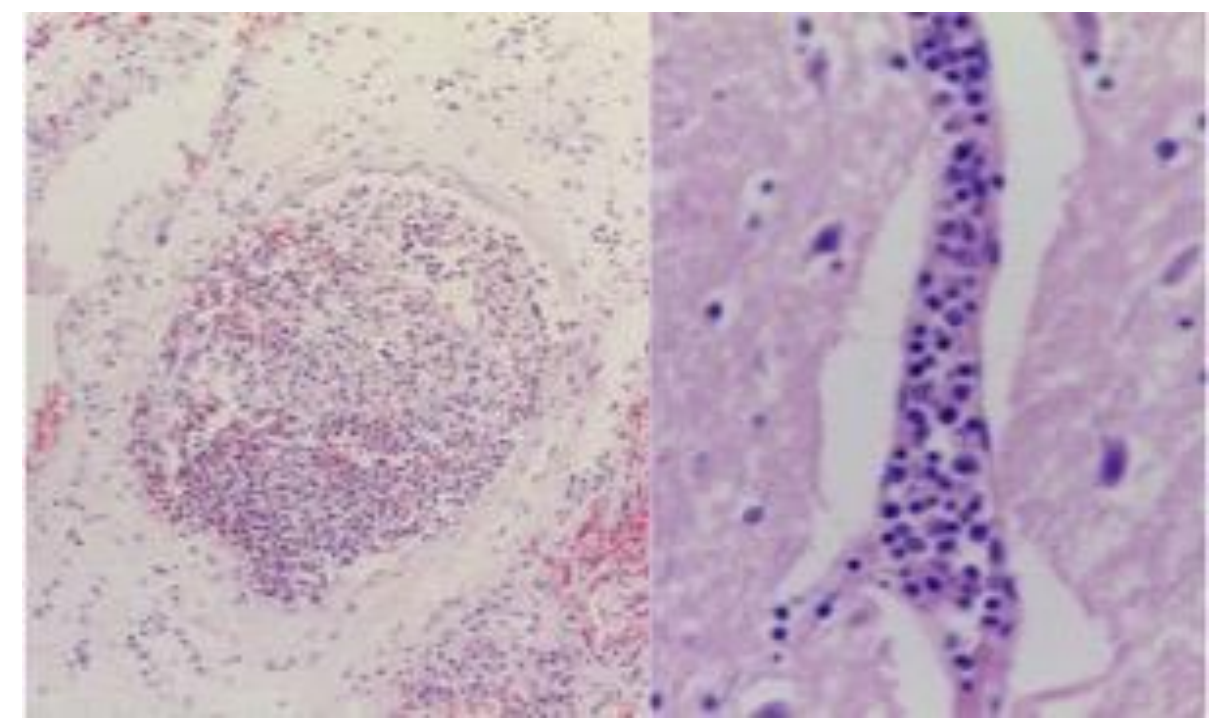

Figure 1: Malignant cells involving vessels of lung (left)(H\&E 100x) and brain (right) (H\&E 600x)

The main autopsy findings were hepatomegaly and splenomegaly. Microscopy study demonstrated large atypical hematopoietic cells strictly confined to the sinusoids of bone marrow and 
spleen, and lumens of the small vessels of the brain, lung, heart, and muscle (Fig. 1). These atypical cells had large irregular hyperchromatic nuclei, prominent nucleoli, and a moderate amount of cytoplasm. The skin had these atypical cells immersed in a thrombus. Bone marrow showed hemophagocytosis and the liver had massive necrosis. Immunohistochemistry showed that these cells were positive for CD2, CD3, CD5, CD7, CD8, Perforin, and Ki-67 (approximately 80\%) (Fig. 2), and negative for CD1a, TdT, CD4, CD20, CD30, LMP1, and CD56. Molecular studies showed monoclonal T-cell receptor gene rearrangement and lack of Epstein Barr Virus infection.

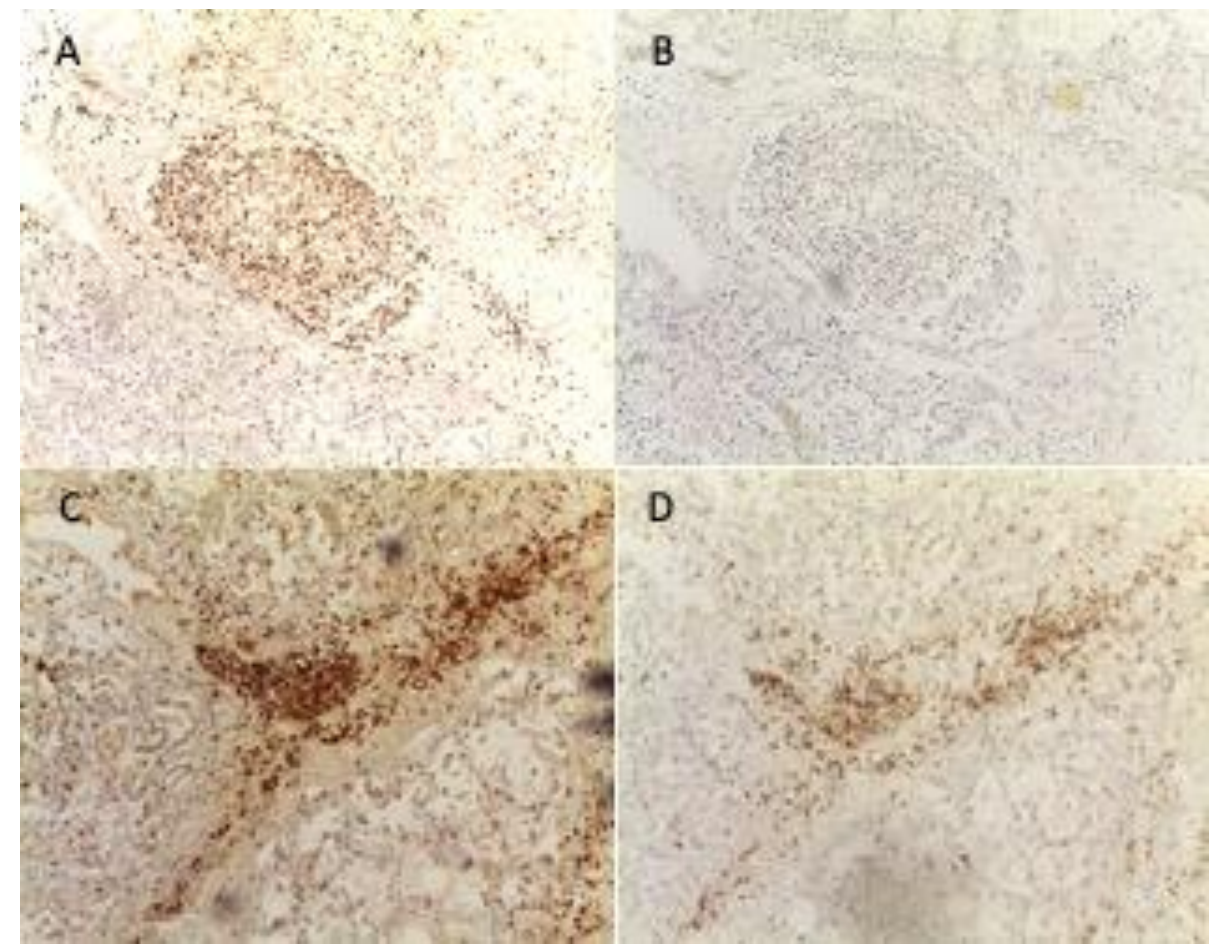

Figure 2: Immunophenotype of malignant cells. (A) Immunohistochemistry (IHC) stains show malignant cells are CD3 positive T lymphocytes (100x). (B) These cells not have an expression to CD20 (100x). (C) They are CD8 positive predominantly (100x) and (D) show expression of other T cell IHC stains like CD5 (100x)

\section{Discussion}

Hepatosplenic T-cell lymphoma (HSTCL) is an aggressive and rare neoplasm, originating from gamma-delta lymphocytes. These cells play a role in the innate, non-specific immune response. They develop from thymus precursors in the bone marrow and lack of major histocompatibility complex restrictions and can be divided into two subpopulations: Vdelta1, mostly represented in the intestine, and Vdelta2, prevalently located in the skin, tonsils, and lymph nodes (Foppoli and Ferreri, 2015). HSTCL has an aggressive clinical course, characterized by hepato-splenomegaly and significant cytopenias, but without significant lymphadenopathy. 
HSTCL occurs more frequently in immunocompromised patients, especially in those receiving long-term immunosuppressive therapy (Shi and Wang, 2015; Yabe et al., 2018). In addition to liver and spleen involvement, the bone marrow can also be affected in up to two-thirds of the cases. Different histopathological patterns have been reported, including exclusively sinusoidal, interstitial, and mixed. The disease may be accompanied by circulating lymphoma cells like in the case report (Foppoli and Ferreri, 2015; Shi and Wang, 2015; Vega et al., 2001). The clinical presentation, in this case, is peculiar and characterized by cytopenias and a very high ferritinemia level. The patient had not immunosuppressive history, B symptoms either visceromegaly detected by clinical or diagnostic imagines.

Histologically, atypical cells tended to percolate between normal hematopoietic cells in bone marrow and spleen as has been shown in other reports (Visnyei et al., 2013; Raza A and Ewton, 2014; Tsunematsu et al., 2014). Neoplastic cells were medium size and some of them had conspicuous nucleoli and irregular nuclear membrane. Interestingly, in our case, intravascular lymphoma cells were identified throughout the body mainly in the brain and lungs, findings which have in common with some other reports (Visnyei et al., 2013; Raza A and Ewton, 2014; Tsunematsu et al., 2014; Ashmore et al., 2015). Small blood vessels of the skin had neoplastic cells immersed in numerous thrombus. According to Jisong Li et al, tumor thrombosis is an extremely rare manifestation in lymphoma and there are only 29 cases of extravascular lymphoma with tumor thrombosis formation reported in English literature (Li et al., 2018). There are no reports of HSTCL with tumor thrombosis in the skin as it was evident in this case. The mechanism of the tumor thrombus development in lymphoma is unknown due to this presentation is sporadic. The previous case reports regarding lymphoma with tumor thrombus have not suggested a potential mechanism for the formation of this finding (Chauhan et al., 2015).

CNS involvement in $\mathrm{T}$ cell lymphomas is not a common event, and it has been described in Primary T Cell Lymphoma - Not Otherwise Specified (NOS) (36.1\%), Angioimmunoblastic (16.9\%), Anaplastic Large Cell Lymphoma - ALK Negative (12.1\%) And ALK-Positive (6.1\%), Extranodal NK/T Cell Lymphoma (7.64\%), Adult T-Cell Leukemia/Lymphoma (7.4\%), and transformed Mycosis Fungoid (8.7\%) (Hui et al., 2014; Guo et al., 2015). In the CNS the neoplastic T cells usually cluster around the blood vessels. The circulating atypical T cells seen at the intravascular compartment of CNS is a finding uncommon. The molecular basis for the distinctive intravascular growth pattern is unknown. Although, several possible explanations have been proposed including defects in the homing receptors CD11a/CD18. These receptors are a heterodimer expressed in B and T-lymphocytes, monocytes, macrophages, neutrophils, basophils, and eosinophils that supports the adhesion to the endothelium through union with ICAM1. These receptors have been demonstrated in the cases of intravascular 
lymphoma; however, it is uncertain the role played by CD11a/CD18 in the pathogenesis of this condition (Hui et al., 2014). Matos et al revealed that chronic lymphocytic leukemia and mantle-cell lymphoma present a higher expression of CD11c and a lower expression of CD11b and CD49d adhesion molecules, unlike marginal B cell lymphoma, showed that the tumor cells presented a higher expression of CD49c and a lower expression of CD11a, CD11b, CD18, CD49, Cd29 and CD54 (Matos et al., 2006; Kamel et al., 2016). A case report of lymphoma with T cell phenotype had a higher expression of CD11a (Setoyama et al., 1992). Aho R. et al showed the widespread immunopositivity for other homing cell adhesion molecules called CD44 in the CNS vessels and parenchyma which facilitate the spreading of malignant lymphocytes within the CNS (Aho et al., 1993). Although adhesion molecules have an uncertain role in the pathogenesis and histologic findings in lymphoma, the dysregulation could promote to the biogenesis of malignant transformation of lymphoma and isolation of intravascular tumor cells in some lymphoma types.

The case report had an immunophenotypic findings compatibles with a cytotoxic pattern. The neoplastic cells were positive to CD2, CD3, CD8, and Perforin, the last is a membrane protein restricted to cytotoxic cells regardless of their activation status and often expressed by gamma/delta T-cell lymphoma (Shi and Wang, 2015; Vega et al., 2001; Visnyei et al., 2013). Molecular study showed EBV absent and T-cell receptor gene rearrangement was defined as monoclonal is habitually seen in HSTCL (Tsunematsu et al., 2014; Ashmore et al., 2015)

The differential diagnosis included other lymphoproliferative processes that may show sinusoidal bone marrow and spleen involvement such as splenic marginal zone B-cell lymphoma. Intravascular Bcell lymphoma was initially thought due to the presence of malignant cells in the vessels. These entities were easily ruled out by the absence of B-cell immunophenotype. Rare cases of intravascular lymphomas have been reported to be of T cell lineage; however, there are not a specific intravascular $\mathrm{T}$ cell lymphomas recognized in the 2016 World Health Organization (WHO) classification and many of these cases have not been evaluated for expression T cell receptor (TCR) gene rearrangement, and not count with spleen or liver sample (Gurion et al., 2016; Federico et al., 2018; Jang et al., 2014; Cerroni et al., 2008; Au et al., 1997; Kuo et al., 2006; Takahashi et al., 2005; Zizi-Sermpetzoglou et al., 2009; Williams et al., 2005). The granular lymphocytic leukemia (LGL) is often found in older adults with autoimmune diseases such as rheumatoid arthritis and systemic lupus erythematosus with an immunophenotype similar to the case reported but generally the TCR is alpha/beta (Yabe et al., 2017; Matutes, 2017; Oshimi, 2017). Patients with aggressive NK cell leukemia/lymphoma often have lymphocytosis which not was found in the case report and furthermore, it shows neoplastic cells with azurophilic cytoplasmic granules and positivity to CD56 with lacks CD3 (Nicolae et al., 2017; Gao et al., 
2017; Tang et al., 2017). NK and T cell precursors lymphoid neoplasms were distinguished from HSTCL by expression of mature immunophenotype and absence of TdT (Jabbour et al., 2006).

\section{Conclusion}

HSTCL is an aggressive type of peripheral T - cell lymphoma characterized by infiltration and proliferation of atypical T-cells within the sinusoids of the spleen, liver, and bone marrow. This case report highlights the importance of considering HSTCL as a differential diagnosis in the clinical setting of young immunocompetent patients with unknown origin fever and extreme hyperferritinemia. Furthermore, this case presents a particular histology finding consisting of intravascular involvement by neoplastic cells mainly in CNS and lungs.

\section{Conflicts of Interest}

The authors declare have no conflicts of interest.

\section{References}

Aho R, Ekfors T, Haltia M, Kalimo H. Pathogenesis of primary central nervous system lymphoma: invasion of malignant lymphoid cells into and within the brain parenchyme. Acta neuropathologica 1993; 86: 71-76.

Ashmore P, Patel M, Vaughan J, Wiggill T, Willem P, van den Berg E, Philip V, Lakha A. Hepatosplenic T-cell lymphoma: a case series. Hematology/oncology and stem cell therapy 2015; 8: 78-84.

Au WY, Shek WH, Nicholls J, Tse KM, Todd D, Kwong YL. T-cell intravascular lymphomatosis (angiotropic large cell lymphoma): association with Epstein-Barr viral infection. Histopathology 1997; 31: 563-567.

Cerroni L, Massone C, Kutzner H, Mentzel T, Umbert P, Kerl H. Intravascular large T-cell or NK-cell lymphoma: a rare variant of intravascular large cell lymphoma with frequent cytotoxic phenotype and association with Epstein-Barr virus infection. The American journal of surgical Pathology 2008; 32: 891-898.

Chauhan A, Garg N, Menias CO, Devine CE, Bhosale PR, Balachandran A. Tumor thrombus as a rare presentation of lymphoma: a case series of 14 patients. American Journal of Roentgenology 2015; 204: W398-W404.

Federico M, Bellei M, Marcheselli L, Schwartz M, Manni M, Tarantino V, Pileri S, Ko YH, Cabrera ME, Horwitz S, Kim WS. Peripheral T cell lymphoma, not otherwise specified (PTCL-NOS). A new prognostic model developed by the International T cell Project Network. British journal of haematology 2018; 181: 760-769.

Foppoli M and Ferreri AJ. Gamma-delta t-cell lymphomas. European journal of haematology 2015; 94: 206-218.

Gao J, Behdad A, Ji P, Wolniak KL, Frankfurt O, Chen YH. EBV-negative aggressive NK-cell leukemia/lymphoma: a clinical and pathological study from a single institution. Modern Pathology 2017; 30: 1100.

Guo X, Li Q, Zhu YP. Childhood hepatosplenic T-cell lymphoma with skin involvement. Indian Pediatrics 2015; 52 : 427428.

Gurion R, Mehta N, Migliacci JC, Zelenetz A, Moskowitz A, Lunning M, Moskowitz C, Hamlin P, Horwitz S. Central nervous system involvement in T-cell lymphoma: A single center experience. Acta Oncologica 2016; 55: 561-566. 
Hui M, Uppin SG, Paul TR, Beerappa N. Hepatosplenic T Cell Lymphoma: A Rare Case Report. Indian Journal of Hematology and Blood Transfusion 2014; 30: 17-20.

Jabbour E, Koscielny S, Sebban C, Peslin N, Patte C, Gargi T, Biron P, Ferme C, Bourhis JH, Vantelon JM, Arnaud P. High survival rate with the LMT-89 regimen in lymphoblastic lymphoma (LL), but not in T-cell acute lymphoblastic leukemia (TALL). Leukemia 2006; 20: 814-819.

Jang YH, Lee SJ, Choi YH, Lee WJ, Kim DW, Kim J, Park TI, Chae YS. Intravascular cytotoxic T-cell lymphoma in a young immunocompetent woman. Annals of dermatology 2014; 26: 496-500.

Kamel AM, El-Sharkawy NM, Osman RA, Abd El-Fattah EK, El-Noshokaty E, Abd El-Hamid T, Kandeel EZ. Adhesion molecules expression in CLL: Potential impact on clinical and hematological parameters. Journal of the Egyptian National Cancer Institute 2016; 28: 31-37.

Kuo TT, Chen MJ, Kuo MC. Cutaneous intravascular NK-cell lymphoma: report of a rare variant associated with EpsteinBarr virus. The American journal of surgical pathology 2006; 30: 1197-1201.

Li J, Tian X, Wang M, Liu W, Guo X, Wang K, Nong L, Wang W, Yang Y. a primary retroperitoneal anaplastic lymphoma kinase-positive anaplastic large cell lymphoma with tumor thrombosis. OncoTargets and therapy 2018; $11: 9007$.

Matos DM, Rizzatti EG, Garcia AB, Gallo DA, Falcao RP. Adhesion molecule profiles of B-cell non-Hodgkin's lymphomas in the leukemic phase. Brazilian journal of medical and biological research 2006; 39: 1349-1355.

Matutes E. Large granular lymphocytic leukemia. Current diagnostic and therapeutic approaches and novel treatment options. Expert review of hematology 2017; 10: 251-258.

Nicolae A, Ganapathi KA, Hoc-Tran T, Liqiang X, Torres-Cabala CA, Nanaji NM, Zha HD, Fan Z, Irwin S, Pittaluga S, Raffeld M. EBV-negative Aggressive NK-cell Leukemia/Lymphoma: Clinical, Pathologic, and Genetic Features. The American journal of surgical pathology 2017; 41: 67-74.

Oshimi K. Clinical Features, Pathogenesis, and Treatment of Large Granular Lymphocyte Leukemias. Internal Medicine 2017; 56: 1759-1769.

Raza A and Ewton A. Hepatosplenic T-cell lymphoma. Blood 2014; 124: 677-677.

Setoyama M, Mizoguchi S, Orikawa T, Tashiro M. A case of intravascular malignant lymphomatosis (angiotropic large-cell lymphoma) presenting memory $\mathrm{T}$ cell phenotype and its expression of adhesion molecules. The Journal of dermatology 1992; 19: 263-269.

Shi Y and Wang E. Hepatosplenic T-Cell Lymphoma: A Clinicopathologic Review with an Emphasis on Diagnostic Differentiation from Other T-Cell/Natural Killer-Cell Neoplasms. Archives of Pathology and Laboratory Medicine 2015; 139: 1173-1180.

Takahashi E, Kajimoto K, Fukatsu T, Yoshida M, Eimoto T, Nakamura S. Intravascular large T-cell lymphoma: a case report of CD30-positive and ALK-negative anaplastic type with cytotoxic molecule expression. Virchows Archiv 2005; 447: 1000-1006.

Tang YT, Wang D, Luo H, Xiao M, Zhou HS, Liu D, Ling SP, Wang N, Hu XL, Luo Y, Mao X. Aggressive NK-cell leukemia: clinical subtypes, molecular features, and treatment outcomes. Blood cancer journal 2017; 7: 660.

Tsunematsu S, Natsuizaka M, Fujita H, Otsuka N, Terashita K, Sato F, Kobayashi T, Nakai M, Tsukuda Y, Horimoto H, Sho T. Hepatosplenic gamma-delta T-cell lymphoma associated with Epstein-Barr virus. Internal Medicine 2014; 53: $2079-2082$.

Vega F, Medeiros LJ, Bueso-Ramos C, Jones D, Lai R, Luthra R, Abruzzo LV. Hepatosplenic gamma/delta T-cell lymphoma in bone marrow: a sinusoidal neoplasm with blastic cytologic features. American journal of clinical pathology 2001; 116: 410- 
419.

Visnyei K, Grossbard ML, Shapira I. Hepatosplenic $\gamma \delta$ T-cell lymphoma: an overview. Clinical Lymphoma, Myeloma and Leukemia 2013; 13: 360-369.

Williams G, Foyle A, White D, Greer W, Burrell S, Couban S. Intravascular T-cell lymphoma with bowel involvement: Case report and literature review. American journal of hematology 2005; 78: 207-211.

Yabe M, Medeiros LJ, Wang SA, Tang G, Bueso-Ramos CE, Jorgensen JL, Bhagat G, Chen W, Li S, Young KH, Miranda RN. Distinguishing between hepatosplenic T-cell lymphoma and $\gamma \delta$ T-cell large granular lymphocytic leukemia: a clinicopathologic, immunophenotypic, and molecular analysis. The American journal of surgical pathology 2017; 41: 82-93.

Yabe M, Miranda RN, Medeiros LJ. Hepatosplenic T-cell Lymphoma: A Review of Clinicopathologic Features, Pathogenesis and Prognostic Factors. Human pathology 2018; 74: 5-16.

Zizi-Sermpetzoglou A, Petrakopoulou N, Tepelenis N, Savvaidou V, Vasilakaki T. Intravascular T-cell lymphoma of the vulva, CD30 positive: a case report. European journal of gynaecological oncology 2009; 30: 586-588. 